Supplement of The Cryosphere, 12, 657-673, 2018 https://doi.org/10.5194/tc-12-657-2018-supplement (C) Author(s) 2018. This work is distributed under the Creative Commons Attribution 4.0 License.

(c) (1)

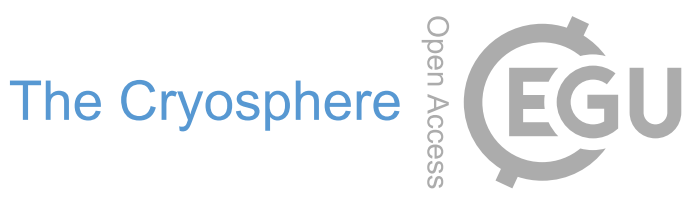

Supplement of

\title{
Change in frozen soils and its effect on regional hydrology, upper Heihe basin, northeastern Qinghai-Tibetan Plateau
}

\section{Bing Gao et al.}

Correspondence to: Dawen Yang (yangdw@tsinghua.edu.cn)

The copyright of individual parts of the supplement might differ from the CC BY 4.0 License. 
Table S1. Comparison of model simulations of the daily streamflow during 2002-2013 with and without frozen soil scheme

\begin{tabular}{llclc}
\hline \multirow{2}{*}{ Station } & \multicolumn{2}{c}{ With frozen soil } & \multicolumn{2}{c}{ Without frozen soil } \\
\cline { 2 - 5 } & NSE & RE (\%) & NSE & RE (\%) \\
\hline Yingluoxia & 0.67 & -1.3 & 0.46 & -15.1 \\
Qilian & 0.61 & 7.8 & 0.50 & -12.3 \\
Zhamashike & 0.73 & 0.3 & 0.38 & -10.2 \\
\hline
\end{tabular}

Table S2. Changes in basin averaged air temperature $\left({ }^{\circ} \mathrm{C}\right)$

\begin{tabular}{lrcc}
\hline & Annual mean & Freezing season & Thawing season \\
\hline $1971-1980$ & -3.43 & -12.54 & 3.07 \\
$1981-1990$ & -3.33 & -12.15 & 2.97 \\
$1991-2000$ & -2.89 & -11.80 & 3.47 \\
$2001-2010$ & -2.19 & -11.11 & 4.19 \\
\hline
\end{tabular}
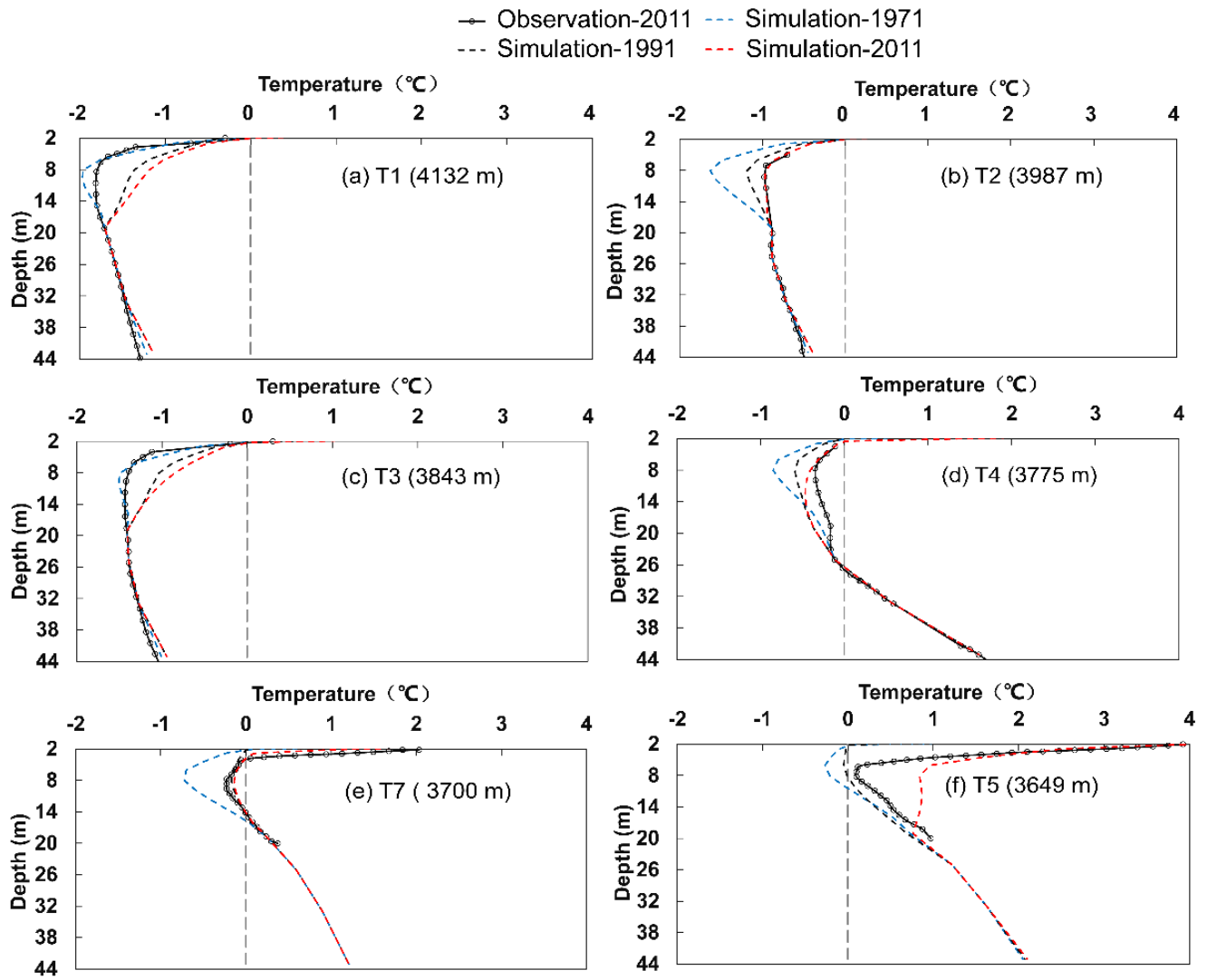

Figure S1. Changes of the ground temperature profiles at 6 boreholes (simulations of 1971, 1991, 2011) and comparison with the observation in 2011 (Ground temperature is the monthly mean value in October, the borehole observations were carried out in the same month of 2011). Legend in (a) applies to all panels. 


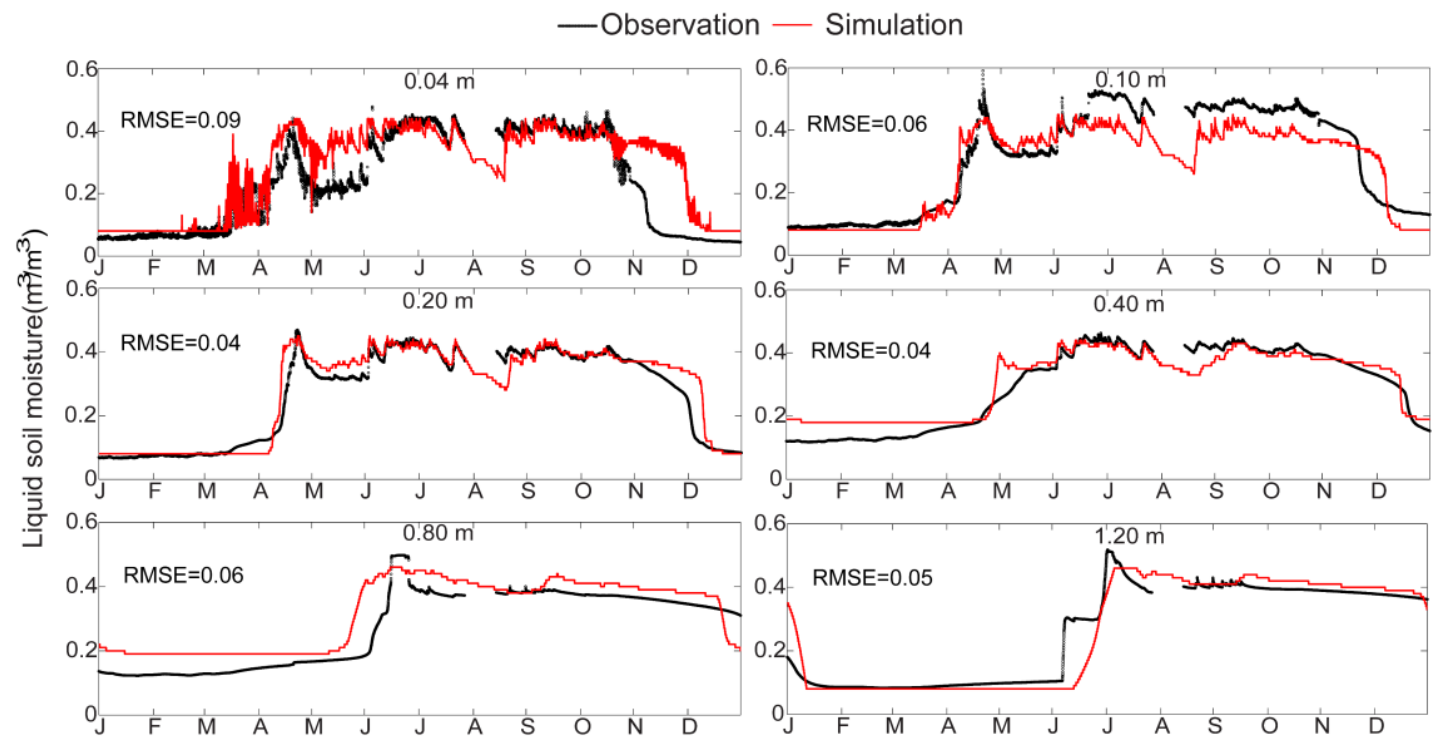

Figure S2. Comparison of the simulated and the observed hourly liquid soil moisture at the A'rou Sunny Slope station (2014 calendar year). Root mean square errors are indicated.

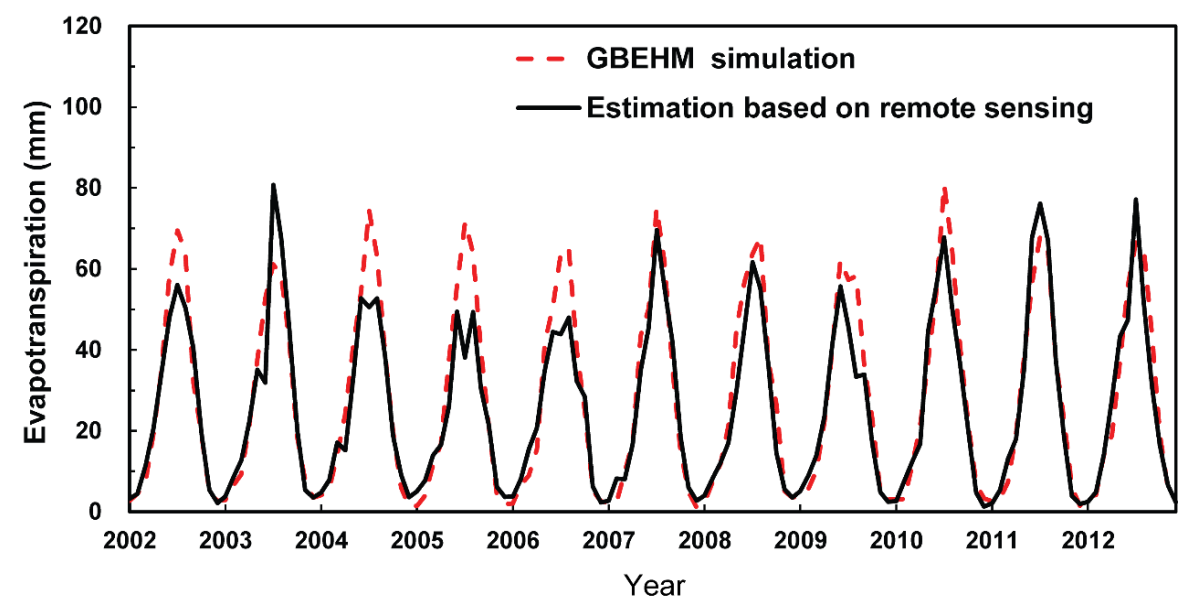

Figure S3. Comparison of simulated monthly evapotranspiration with a remote-sensing-derived estimate (Wu, 2013) for the period of 2002 to 2012. 


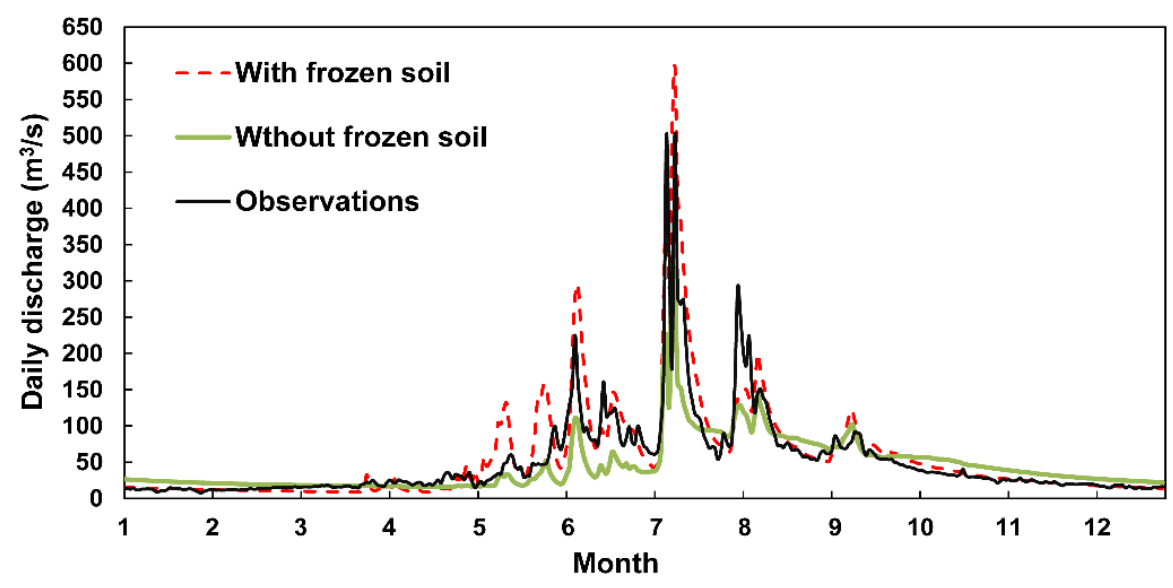

Figure S4. Comparison of the model simulated daily streamflow at the Yingluoxia station with and without frozen soil scheme in 2002.

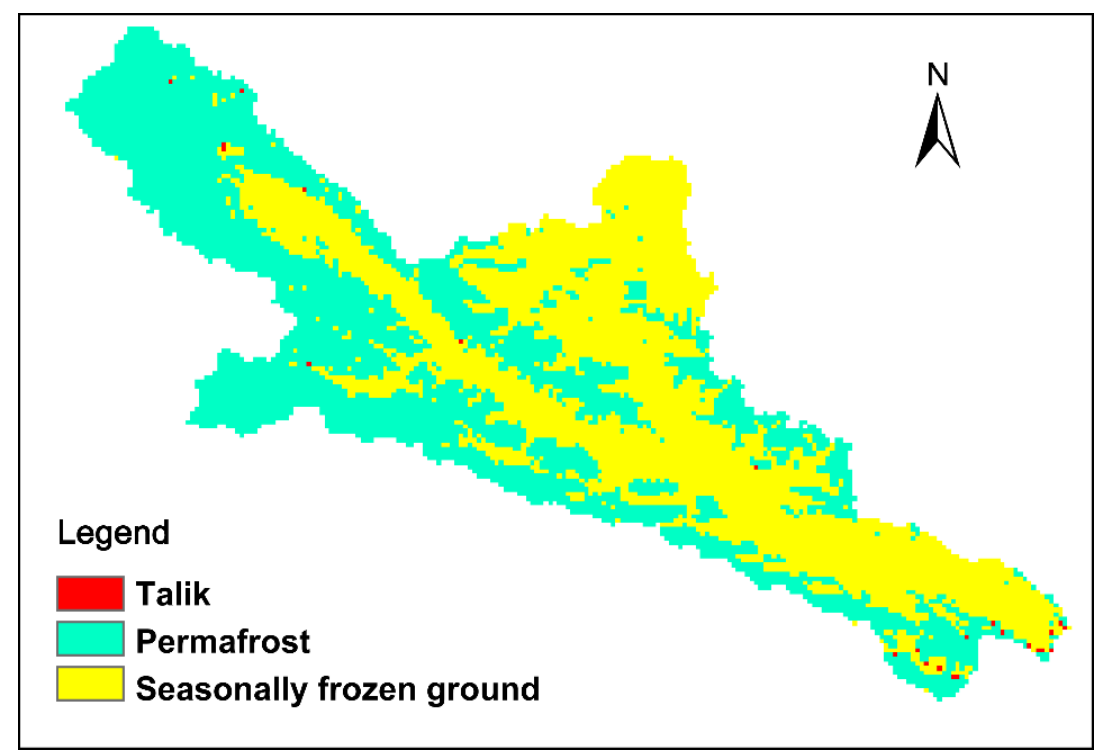

Figure S5. Model simulated taliks in the period of 2001-2010. 


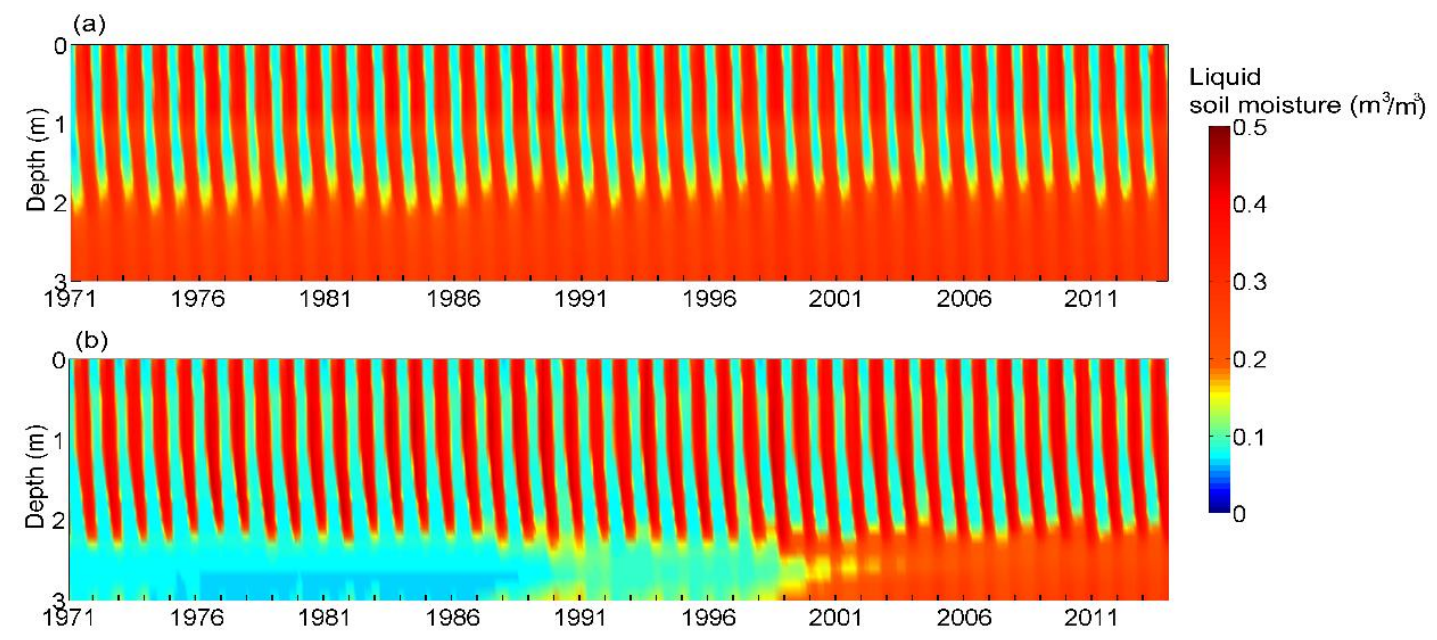

Figure S6. Spatially averaged monthly liquid soil moisture simulated from 1971 to 2013 for two elevation intervals: (a) seasonally frozen ground between 3300 and $3500 \mathrm{~m}$; (b) permafrost that degraded to seasonally frozen ground between 3500 and $3700 \mathrm{~m}$.

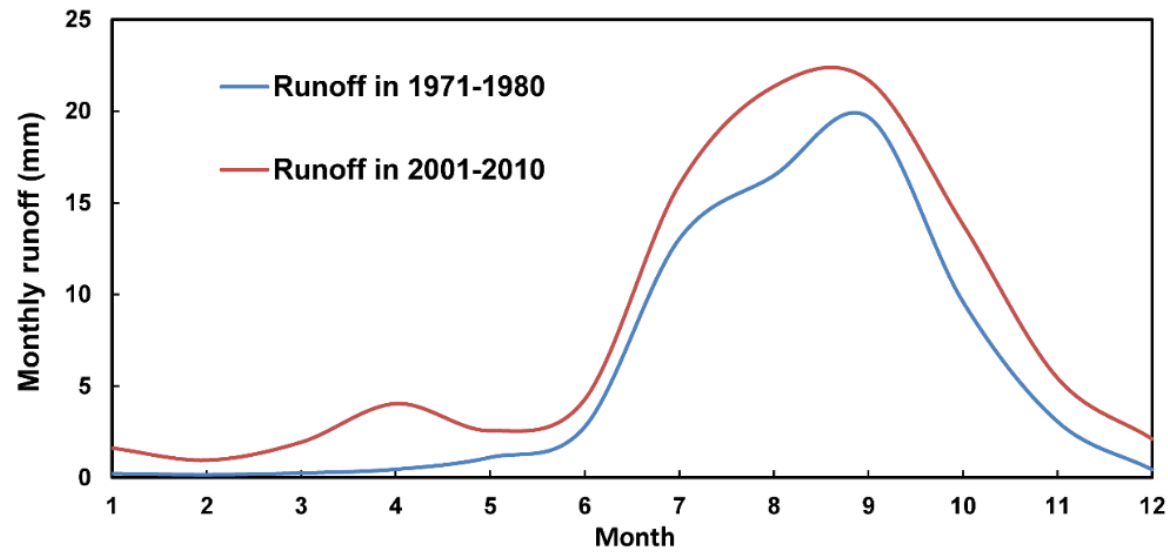

Figure S7. Spatial averaged monthly runoff from the area with elevation of 3500-3700 m, where covered by permafrost in 1971-1980 and changed into seasonally frozen ground in 2001-2010. 